\title{
Discontinuous Precipitation in Al-8\% Mass.Mg Alloy under the Effect of Temperature
}

\author{
Said Bensaada, Mohamed Tewfik Bouziane, Ferhat Mohammedi
}

Laboratoire Larhyss, Université Mohamed Khider BP Biskra, Biskra, Algeria.

Email: Bensaada52@yahoo.fr

Received February $4^{\text {th }}, 2011$; revised April 20 $0^{\text {th }}, 2011$; accepted June $23^{\text {rd }}, 2011$.

\begin{abstract}
The precipitation in the alloy Al-Mg system has been the subject of many theoritical and experimental investigations that have contributed to the understanding of the different mechanisms which control them. The purpose of this work is to clarify the effect of temperature on the mechanisms of these during ageing of Al-8\% mass.Mg alloy. The techniques of analysis used in this respect are the optical microscopy, the X-ray diffraction and the micro hardness Vickers.
\end{abstract}

Keywords: Alloy Al-Mg, Precipitation, Temperature

\section{Introduction}

The transformations of the most significant phases are those which appear in the supersaturated solid solutions representing only one phase $\alpha_{0}$ in equilibrium and of which the steady state corresponds to two phases. One $\alpha$ depleted in alloy components and of the same structure of the initial phase $\alpha_{0}$ and other phase precipitate $\beta$ rich in alloy components and of different structure. This transformation is indicated by the term of precipitation and corresponds to the reaction [1]:

$$
\alpha_{0}=\alpha+\beta
$$

The processes of precipitation which are gouverned by diffusion phenomenon are generally classified in two principal categories:

- The continues precipitation (or nucleation) is homogeneous and completely appears randomely in the whole alloy. One of the principal characteristics of this reaction is the continues variation of the lattice parameter of the initial phase $\alpha_{0}$ and of the concentration of the solute content.

-And the discontinuous precipitation where nucleation is heterogeneous leading to the presence of two distinct regions. One is transformed into alternate lamellar form $(\alpha+\beta)$ behind a mobile grain boundary and the other not. They takes place initially and preferably on heterogeneities of the matrix phase $\alpha_{0}$ which they can be dislocations, surfaces of impurities or grain boundaries. Its characteristic during ageing is the discontinuous variation of the lattice parameter of the matrix phase [2].

\section{Precipitation in the Alloy Al-Mg System}

Precipitation in this alloys system is characterized by intermediate states exibits to the metastable phases according to this scheme [3-10].

$$
\alpha_{0} \rightarrow \text { G.P } \quad \text { Zones } \rightarrow \beta^{\prime \prime} \rightarrow \beta^{\prime} \rightarrow \beta
$$

The stage of pre-precipitation in this system of alloy leads to the formation of G.P zones (small domain rich on solute content). Different technique were used for the description of G.P zones in this alloy system, such as the diffraction of X-rays with high angles used by Dauger and all [11] in alloy Al-12\% mass.Mg. The measurements of the resistivity carried out in alloy Al-10\% mass.Mg and which show an increase in the resistivity during ageing [12-14] and an electron microscopy is used on the same alloy [15].

Some authors [16,17] assume that the formation of G.P zones at room temperature is only for magnesium rates beyond $10 \%$ in atoms, whereas others estimate that this critical rate is about $5 \%$ in magnesium atoms $[18,19]$.

An increase in the temperature of ageing around $100^{\circ} \mathrm{C}$ [20] led to the dissolution of G.P zones and the particles $\beta^{\prime \prime}$. Thus allowing also the formation of intermediate phase $\beta^{\prime}$, metastable, semi-coherent and with a composition of $\mathrm{Al}_{3} \mathrm{Mg}_{2}$ of hexagonal structure. The precipitates $\beta^{\prime}$ are formed by nucleation and growth on the structural defects of the matrix. Their growth leads to a total loss of coherence by arrangement of the dislocations to the $\alpha / \beta^{\prime}$ interface and consequently to the formation of the stable phase $\beta$ of the same composition than the 
phase $\beta^{\prime}$ but of cubic with centered faces structure [20]. However, the transformation mechanisms of $\beta^{\prime \prime}$ phase on $\beta^{\prime}$ and of $\beta^{\prime}$ on $\beta$ in equilibrium phase are not yet clear. It is known that plastic deformation introduces defects into the matrix after quenching leading to the acceleration of the precipitation process. However in this alloy system the ageing at high temperatures can start in addition to the process of precipitation, the process of recrystallization which can involve a slow down of the precipitation process gouverned by diffusion. This means that the recrystallisation led to the formation of a new matrix containing much less dislocations and of fine grains than those of the annealed alloy. But the nucleus formation of a new phase within a solid solution supersaturated and deformed after quenching, can oppose to the movement of grain boundaries and consequently, slow the recrystallisation and leads of an interaction between the precipitation and the recrystallization.

Indeed for the creation of the homogenoues structure of the supersaturated solid solutions generally consist with a an elevation of the load breaking by hardeness. The increase in hardness in the alloy Al-Mg system perhaps obtained by an increase in the magnesium content [21-25]. However in alloys hardened by ageing, the mechanical properties are related on the size and the dispersion of the particles and their interaction with mobile dislocations. In the same way the mechanism of hardening is controlled by the shearing of these particles by mobile dislocations. This would explain the reduction in ductility accompanying the hardening observed [26,27] $\mathrm{du}$ to the stackings of dislocations, caused by the stress fields surrounding the particles.

\section{Experimental Methods}

Alloy $\mathrm{Al}-8 \%$ mass.Mg was prepared for the investigation by vacum induction melting of the elements $(\mathrm{Al}$ and $\mathrm{Mg})$ of high purity. The ingots were then homogenized at $440^{\circ} \mathrm{C}$ for 44 hours followed by an ice quenching. The deformation of the samples used for ageing at $160^{\circ} \mathrm{C}$, $220^{\circ} \mathrm{C}$ and $270^{\circ} \mathrm{C}$ are obtained by colled rolling. The ageing conditions are simultaneously obtained from literature and from the equilibrium diagram of the alloy $\mathrm{Al}-\mathrm{Mg}$ system. In this respect the vacuum annealing was performed. The optical microscopy, the diffraction of $\mathrm{X}$-rays and the microhardness are the principal methods of analysis. The metallographic observation were performed after etching in the solution of Keller $(07 \mathrm{ml}$ of $\mathrm{HF}, 09 \mathrm{ml}$ of hydrochloric acid, $20 \mathrm{ml}$ of nitric acid and $85 \mathrm{ml}$ of distilled water).

\section{Results and Discussion}

In order to make in evidence the effect of the tempera- ture on the mechanisms of precipitation in alloy $\mathrm{Al}-8 \%$ mass.Mg, we have chosen three temperatures of ageing $\left(160^{\circ} \mathrm{C}, 220^{\circ} \mathrm{C}\right.$ and $\left.270^{\circ} \mathrm{C}\right)$ favorable to this type of transformation.

\subsection{Ageing at $160^{\circ} \mathrm{C}$}

The interesting feature of this alloy is that the plastic deformation induced twins and dislocations which can play an essential role to stimulate the process of precipitation. However ageing at the temperature of $160^{\circ} \mathrm{C}$ is only favorable to the continuous precipitation and with the intermediate phase $\beta^{\prime}$ is characterized by an interesting aspect as shown in Figure 1(a). This structure is called Widmannsttaten, it is probably the direct conesquence of the germination of the phase $\beta^{\prime}$. The particles of this phase are developed in the form of needles (Figure 1(b)) and when the nucleation and the growth of the particles $\beta^{\prime}$ are performed, i.e. the totality of the phase $\beta^{\prime}$ is formed and total coherence is lost, thus we have the transformation of $\beta^{\prime}$ on $\beta$ in equilibrium phase. The

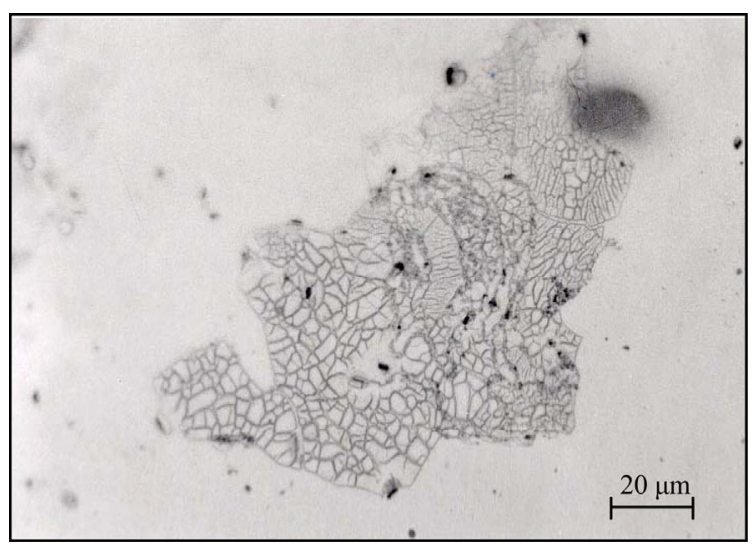

(a)

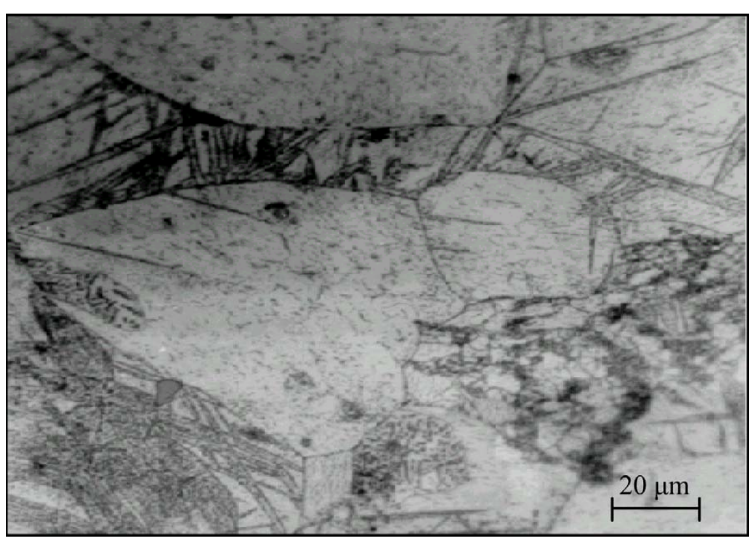

(b)

Figure 1. Structural evolution of Al-8\% mass.Mg alloy, homogeneised at $440^{\circ} \mathrm{C}$ during $44 \mathrm{~h}$, quenched in ice, deformed of $35 \%$, aged at $160^{\circ} \mathrm{C}$ during $4 \mathrm{~h}$ (a) and during 18 h (b). 
evolution of microhardness HV during ageing is represented in Figure 5(a). We can notice that a maximum hardening is obtained after an annealing of 90 hours then decreases during the extension of ageing time.

\subsection{Ageing at $220^{\circ} \mathrm{C}$}

During ageing at $220^{\circ} \mathrm{C}$, the presence of the lamellar precipitate is confirmed by optical microscopy as shown in Figure 2(a) and (b). This means that this temperature is only favorable to discontinuous precipitation developing on the grain boundaries. The morphology of the precipitate varies from a region to another. In the same way the mechanism S is more dominating Figure 3(a) and (b) The microhardness starting increases from the value obtained at the quenched condition until a maximum corresponding to a duration of 63 hours then to decrease Figure 5(b). One can deduce that the maximum hardening is obtained when the totality of the intermediate phase $\beta^{\prime}$ is formed. The transformation of $\beta^{\prime}$ into equilibrium phase

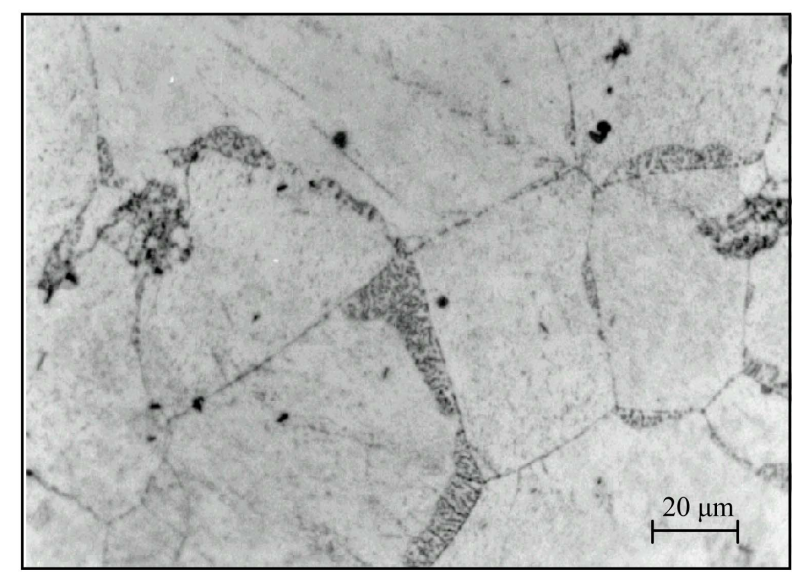

(a)

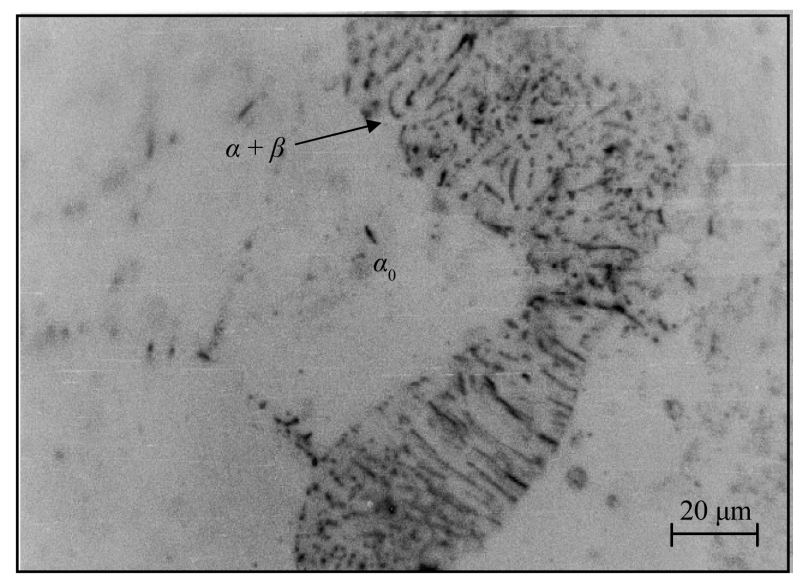

(b)

Figure 2. Structural evolution of Al-8\% mass.Mg alloy, homogeneised at $440^{\circ} \mathrm{C}$ during $44 \mathrm{~h}$, quenched in ice, aged at $220^{\circ} \mathrm{C}$ during $22 \mathrm{~h}$.
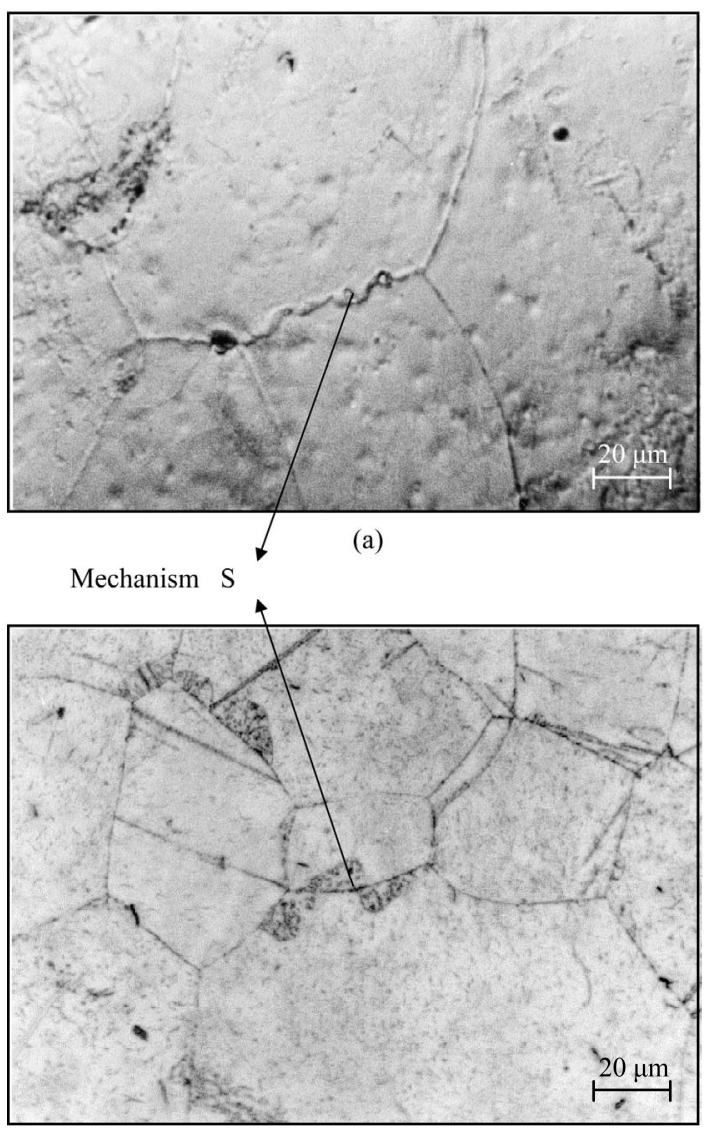

(b)

Figure 3. Structural evolution of $\mathrm{Al}-8 \%$ mass.Mg alloy, homogeneised at $440^{\circ} \mathrm{C}$ during $44 \mathrm{~h}$, quenched in ice, aged at $270^{\circ} \mathrm{C}$ during $22 \mathrm{~h}$ and with S-mechanism.

$\beta$ leads to the decrease of hardness. In the same way the diffraction of X-rays confirms the precipitation in this alloy Figure 4.

\subsection{Ageing at $270^{\circ} \mathrm{C}$}

With the temperature of ageing at $270^{\circ} \mathrm{C}$, only the continoues precipitation appears. For high temperatures discontinuous precipitation disappears, because the volume diffusion prevents its growth and its nucleation becomes difficult (slows down the movement of the reaction front). The increase in the temperature accelerates relatively the diffusion process. Best hardening is obtained after 54 hours of duration Figure 5(c) and more we prolong ageing, we lose hardness more.

\section{Conclusions}

The whole results presented in this work reflects in particular the effect of the temperature on the mode of precipitation in alloy $\mathrm{Al}-8 \%$ mass.Mg. A predeformation with ageing at $160^{\circ} \mathrm{C}$ reveals the structure of Widmannsttaten, with a growth in needles form and leading 


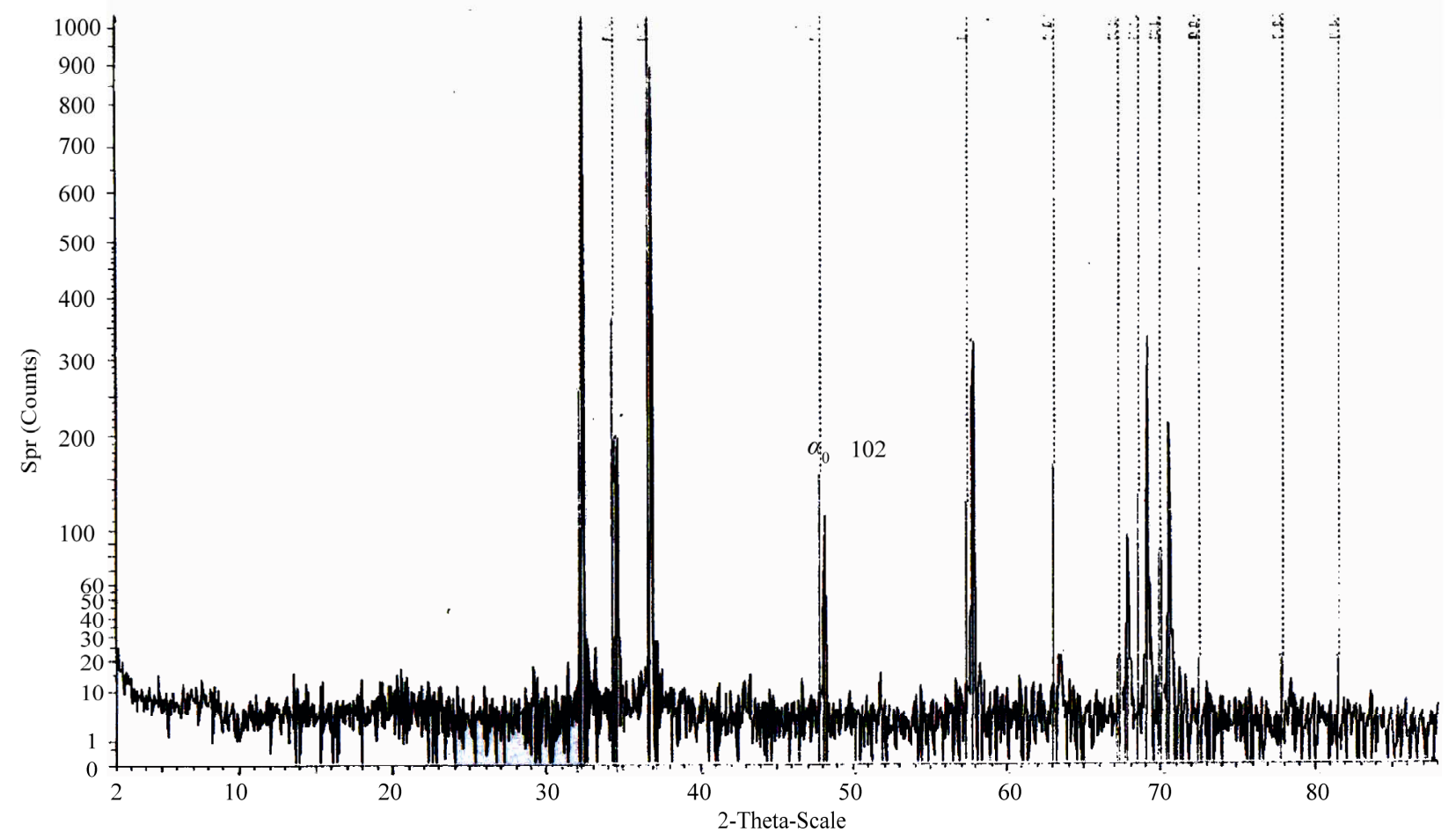

(a)

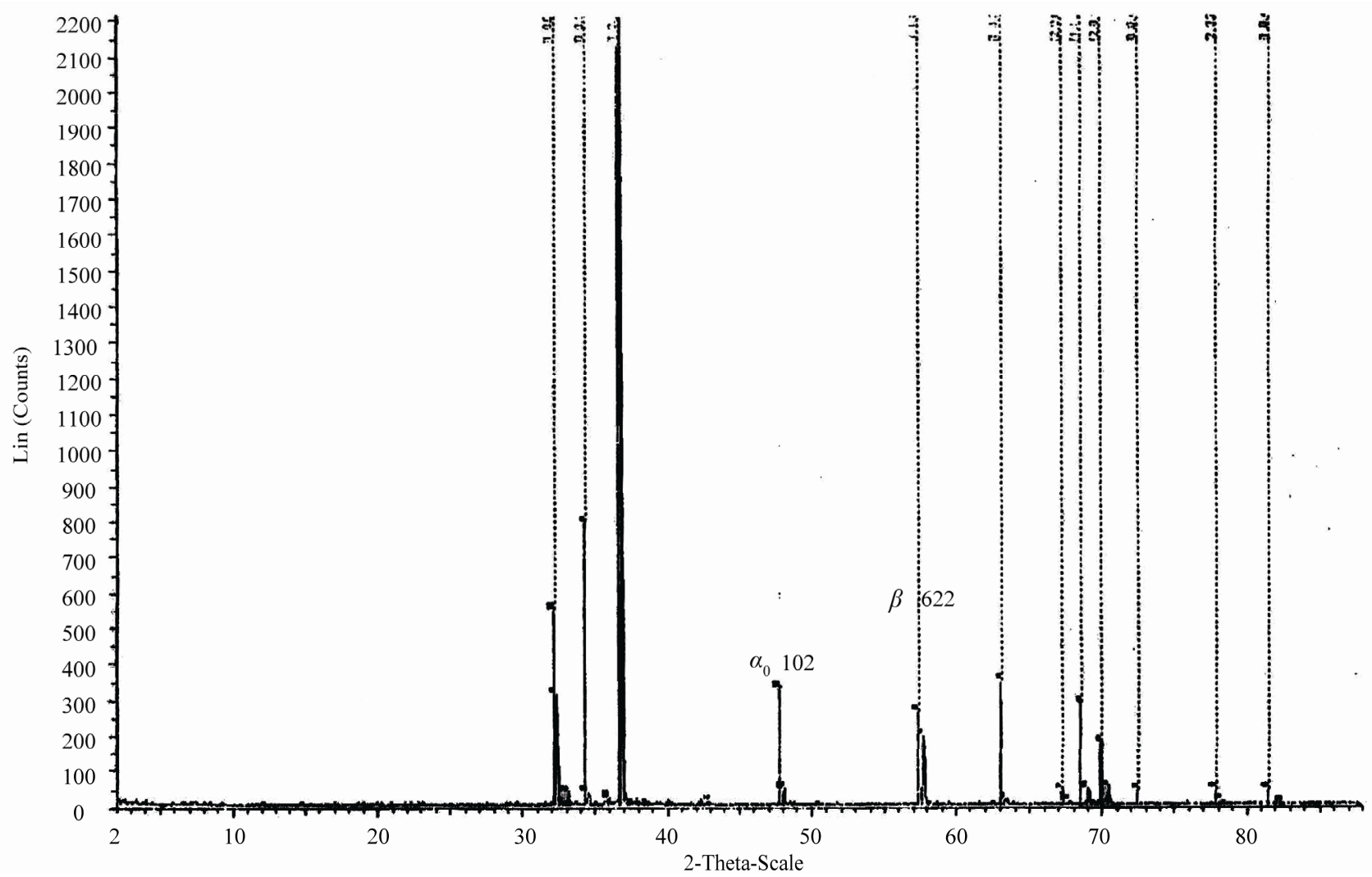

(b)

Figure 4. Xrays difraction of Al-8\% mass.Mg alloy, homogeneised at $440^{\circ} \mathrm{C}$ during $44 \mathrm{~h}$, quenched in ice (a), aged at $160^{\circ} \mathrm{C}$ during $22 \mathrm{~h}$ (b). 


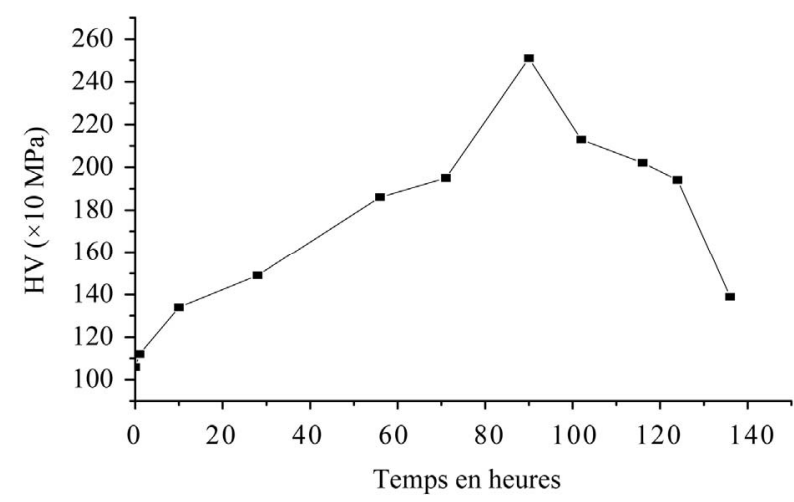

(a)

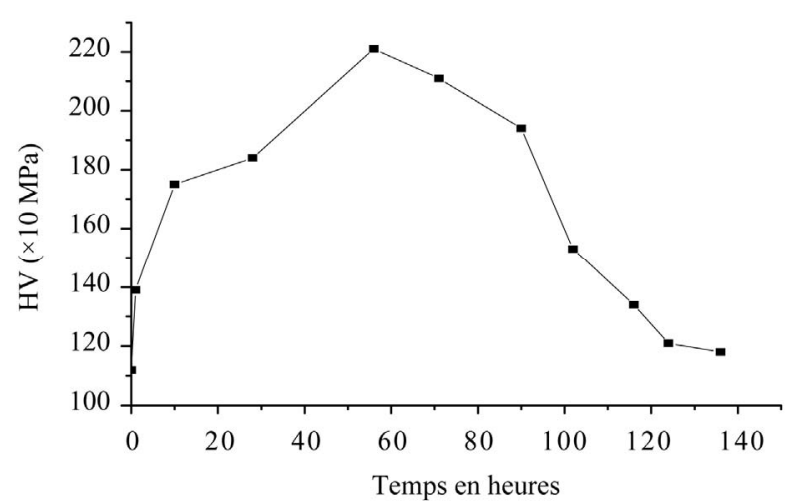

(b)

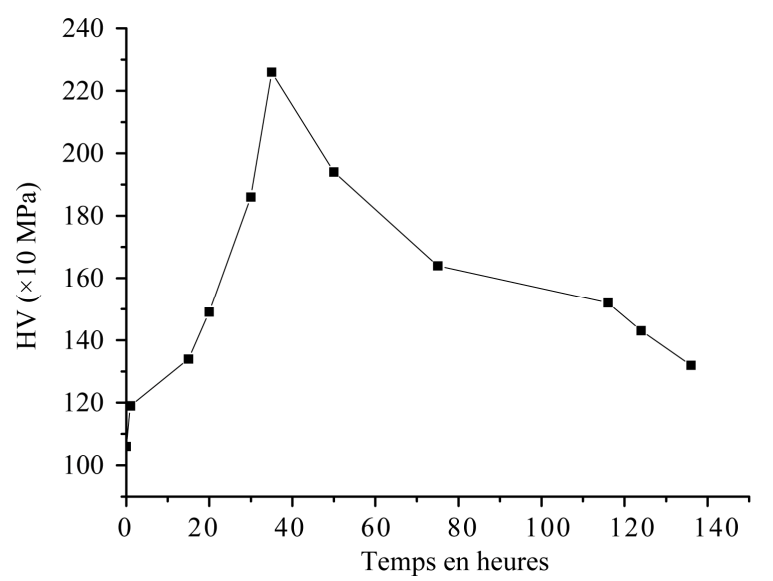

(c)

Figure 5. Microhardness (HV) evolution structural of Al-8\% mass.Mg alloy, homogeneised at $440^{\circ} \mathrm{C}$ during $44 \mathrm{~h}$, quenched in ice, aged at $160^{\circ} \mathrm{C}(\mathrm{a})$, at $220^{\circ} \mathrm{C}$ (b) and at $270^{\circ} \mathrm{C}$ (c).

to a continuous precipitation. Continues precipitation is favoured at high and low temperature, while discontinuous precipitation dominates at intermediate temperatures. High temperatures accelerate relatively the diffusion process and the mechanism $\mathrm{S}$ is more dominating in discontinuous precipitation. Hardening was observed at all temperatures of ageing, however the extension of ageing time of bearing led to a hardness fall.

\section{Acknowledgements}

The authors gratefully acknowledge the financial support by the M.E.S.R.S Ministry for the Higher Education and the Requirend scientist of Algeria under research laboratory LARHYSS, University of Biskra.

\section{REFERENCES}

[1] M. S. Sulonen, Acta Metallurgica, Vol. 12, 1964, pp. 743-753. doi:10.1016/0001-6160(64)90227-5

[2] W. Gust, "Untersuchung zur diskontinuirlichen Auscheidung in Metallischen Systemen," Phase Transformations, Vol. 1, Serie 3, No. 11, June 1987, pp. 145-151.

[3] T. B. Massalski, "Binary Alloy Phase Diagram, ASM International," Metals Park, No. 10, July 1991, p. 170.

[4] J. W. Cahn, "Discontinuous Dissolution in aged Alloys," Acta Metallurgica, No. 10, September 1962, pp. 907-912.

[5] J. L. Murray, Bull, Alloy Phase Diagrams, No. 3, August 1982 , p. 60

[6] A. Kelly and R. B. Nicholson, "Progress in Materials Science," Ed. B. Chalmers Division of Engineering and Applied Physics, Harvard University, Cambridge, No. 15, October 1966, p. 209.

[7] P. G. Shewmon, "Fondamentals of Grain and Interphase Boundary Diffusion," Transactions of the American Institute of Mining and Metallurgical Engineers, No. 2, March 1965, pp. 736-738.

[8] L. I. Kaigorodova, N. M. Byniov and M. F. Kamarova, Fizika Metallov Metalloveden (F.M.M), 53, No. 3, March 1982, p. 542

[9] T. Sato, Y. Kojima and T. Takahashi, Metallurgical and Materials Transactions A, No. 13, July 1982, pp. 13731375.

[10] T. Malis and M. C.Chaturvedj, Journal of Materials Science, No. 17, October 1982, p. 1479. doi:10.1007/BF00752263

[11] N. N. Byinov and L. I. Kaigorodovam, Fizika Metallov Metalloveden (F.M.M), Vol. 59, No. 1, January 1985, p. 91.

[12] M. Van Rooyen, J. A. Sinte Maartensdijk and E. J. Mittemeiger, Metallurgical and Materials Transactions A, No. 19, November 988, pp. 2473-2477.

[13] D. Hamana, V. L. Avanessov and A. F. Sirenko, Scripta Metallurgica et Metarialia, No. 24, December 1990, pp. 2013-2017

[14] A. Dauger, J. P. Guillot and J. Caisso, Compte Rendu Académie des Sciences Paris, No. 2, February 1973, pp.225-229

[15] M. Roth and J. M. Raynal, "Cellular Precipitation in Supersaturated Solid Solutions," Journal of Applied Crystallography, No. 7, June 1974, pp. 219. doi:10.1107/S0021889874009320 
[16] A. Dauger, E. K. Boudili and M. Roth, Scripta Materialia, No. 10, October 1976, pp. 1119-1123.

[17] M. Bernole, R. Graf and P. Guyot, Philosophical Magazine, No. 28, September 1973, pp. 771. doi:10.1080/14786437308220982

[18] R. Nozato and G. Nakai, Materials Transactions JIM, No. 18, November 1977, pp. 679-684.

[19] J. W.Cahn, Acta Metallurgica, No. 10, 1962, pp. 907-911

[20] W. A. Pollard, Journal Institute of Metals, No. 3, July 1964, pp. 339-342.

[21] M. Hillert, "The Mechanism of phase transformations in Crystalline Solids," Journal de Physique et Le Radium, No. 23, June 1984, p. 835

[22] K. Osamura and T. Ogura, Metallurgical and Materials
Transactions A, No. 15, September 1984, pp. 835-838.

[23] M. Bernole, J. Raynal and R. Graf, Journal of Microscopy, No. 8, August 1969, pp. 831-833

[24] C. Pensiri, T. Federighi and S. Ceresara, Metallurgical and Materials Transactions, No. 2, August 1963, pp. 1122-1124.

[25] K. Detert and L. Thomas, Acta Metallurgica, No. 12, December 1964, p. 431

[26] H. Suzuki, M. Kanno and T. Kitayama, Journal of Japan Institute of Light Metals, No. 28, May 1978, pp. 292-295.

[27] Y. Kojima and K. Watanabem, "In Precipitation from Solid Solution," Journal of Japan Institute of Light Metals, No. 30, March 1980, pp. 270-273. 